\title{
Challenging Issues in the Management of Cardiovascular Risk Factors in Diabetes During the COVID-19 Pandemic: A Review of Current Literature
}

Leili Rahimi · Mojtaba Malek · Faramarz Ismail-Beigi • Mohammad E. Khamseh

Received: June 8, 2020 / Published online: July 6, 2020

(C) The Author(s) 2020

\section{ABSTRACT}

The COVID-19 outbreak was declared a pandemic on March 2020. Many patients with SARS-CoV-2 infection have underlying chronic medical conditions such as diabetes, cardiovascular disease (CVD), and hypertension. Patient-related outcomes are worse if there are associated comorbidities. We do not have enough evidence regarding the most appropriate management of patients with diabetes during COVID-19 infection. Insulin resistance and CVD together increase the inflammatory state of the body, which can contribute to and perhaps mediate the increase of COVID-19 severity. Hence, in addition to management

Digital Features To view digital features for this article go to https://doi.org/10.6084/m9.figshare.12489641.

L. Rahimi · F. Ismail-Beigi

Department of Medicine, Case Western Reserve

University, University Hospitals Cleveland Medical

Center, Cleveland, $\mathrm{OH} 44106$, USA

M. Malek

Research Center for Prevention of Cardiovascular Disease, Institute of Endocrinology and Metabolism, Iran University of Medical Sciences (IUMS), Tehran, Iran

M. E. Khamseh $(\bowtie)$

Endocrine Research Center, Institute of

Endocrinology and Metabolism, Iran University of

Medical Sciences (IUMS), Tehran, Iran

e-mail: khamseh.m@iums.ac.ir

of dysglycemia, other CVD risk factors should be targeted. We explore the possible pathophysiologic links between diabetes and COVID19 and discuss various options to treat dysglycemia, hypertension, and dyslipidemia in the era of COVID-19.

Keywords: Cardiovascular risk; COVID-19; Diabetes; Diabetes management

\section{Key Summary Points}

Many patients with SARS-CoV-2 infection have underlying chronic medical conditions.

Patient-related outcomes are worse if there are associated comorbidities.

Insulin resistance and cardiovascular disease contribute to the increased severity of COVID-19.

Management of dysglycemia, hypertension, and dyslipidemia should be targeted individually in patients with COVID-19 infection.

SARS-CoV-2 patients are vulnerable to the development of thromboembolic disease. A personalized approach to antithrombotic/thromboembolism prophylaxis is recommended. 


\section{INTRODUCTION}

In December 2019, severe Acute Respiratory Syndrome-Coronavirus-2 (SARS-CoV-2) caused clusters of patients with pneumonia in Wuhan, Hubei Province, China [1, 2]. On 11 March 2020, the World Health Organization (WHO) declared the COVID-19 outbreak a pandemic [3]. To date, 5,103,006 confirmed cases and 333,401 deaths have been reported globally [4].

Many patients with COVID-19 have associated comorbidities. Hypertension is reported in about one-fifth of the patients, followed by diabetes in 9.7\% and CVD in 8.4\%. In addition, patients with underlying comorbidity have more severe infections and worse clinical outcomes $[5,6]$. In another systematic review on risk factors of critical and mortal COVID-19, diabetes (OR 3.68, 95\% CI 2.68-5.03), CVD (OR 5.19, 95\% CI 3.25-8.29), and hypertension (OR: 2.72, 95\% CI 1.60-4.64) were significantly more prevalent in the critical than non-critical group [7]. Higher case fatality rates (CFR) have been reported in COVID-19 patients with CVD (13.2\%), diabetes (9.2\%), and hypertension $(9.2 \%)$, while the rate is $1.4 \%$ in those with no comorbidities [8].

In this review, we will examine what is known concerning the use of various classes of medications commonly used in the treatment of patients with type 2 diabetes (T2DM) in the era of COVID19; this includes treatments of patients either without or during active infection with SARSCov-2 virus. It should be pointed out that some of the recommendations detailed below are based on the best judgment of physicians and endocrinologists with first-hand experience in the care of such patients and not on results of extensive clinical trial data. This article is based on previously conducted studies and does not contain any studies with human participants or animals performed by any of the authors.

\section{POSSIBLE PATHOPHYSIOLOGIC LINKS BETWEEN DIABETES AND COVID-19}

Type 2 diabetes mellitus (T2DM) is a prevalent disease globally. It has been recognized as a primary risk factor for the development of severe pneumonia due to respiratory viral infections [9]. A reciprocal interaction has been identified between COVID-19 and diabetes. Angiotensin-convertingenzyme 2 (ACE2) is recognized as the receptor for the virus. Viral entry might be facilitated by hyperglycemia, which upregulates ACE2 expression on cell surfaces of the pulmonary system [10].

Severe SARS CoV- 1 infection has been associated with prolonged hyperglycemia in people without pre-existing diabetes. Potential direct $\beta$-cell damage caused by SARS-CoV-2 might lead to insulin deficiency and worsening of hyperglycemia [11]. Furthermore, hyperglycemia promotes the synthesis and release of proinflammatory cytokines, leading to oxidative stress, which mediates tissue inflammation. Chronic inflammation might be among the underlying mechanisms contributing to a higher propensity to infection and worse outcomes. In addition, hyperglycemia is associated with impaired lymphocyte proliferation and neutrophil functions [12]. Patients with COVID-19 commonly present with lymphocytopenia and leukopenia. Lymphocytopenia has been shown to correlate with prognosis in patients with COVID-19 [13].

Furthermore, inflammatory cytokines including interleukin-6 (IL-6), C-reactive protein, and coagulation activity are increased in COVID-19 infection [14]. They are also associated with the infection severity [15]. In T2DM, the inflammatory response is enhanced and an imbalance between coagulation and fibrinolysis takes place, with increased levels of clotting factors and endothelial dysfunction. Vascular inflammation and endothelial dysfunction are parts of other co-existing chronic conditions, namely hypertension and CVD [16].

\section{TREATMENT OF HYPERGLYCEMIA, HYPERTENSION, AND OTHER CVD RISK FACTORS IN THE CONTEXT OF COVID-19}

\section{Glucose-Lowering Medications and COVID-19}

Currently, we do not have enough evidence regarding the most appropriate management of 
patients with diabetes during COVID-19 infection. People with T2DM might experience glycemic decompensation. Hence, more frequent blood glucose monitoring and rigorous glucose control seem reasonable to avoid serious complications. Moreover, selection of appropriate treatment regimens needs careful consideration. Although treatment of dysglycemia is the main concern, the importance of other CVD risk factors cannot be overemphasized.

\section{Use of Insulin in Patients with COVID-19}

There are not enough studies on the proper use of insulin in patients with T2DM in the era of COVID-19, and specifically once the patient has become infected. As noted above, hyperglycemia per se stimulates ACE2 expression and, as the "receptor" for the virus, it may play an important role in mediating the severity of COVID-19. It is also possible the overexpression of ACE2 plays an important role in the apparent increased susceptibility of patients with T2DM to acquiring the infection. Insulin is commonly used in the management of T2DM especially when the disease has been well established and the patient's beta cells are "exhausted." Of course, in patients with T1DM, insulin use is mandatory. Hence, insulin should continue to be used prior to any infection with the aim of achieving near-normal levels of glycemia safely.

In patients with diabetes who are admitted to the hospital because of COVID-19, glycemic management should be continued with close monitoring. In addition to hyperglycemia of diabetes, stress hyperglycemia, i.e., elevation of glucose in the absence of diabetes that results from elevated epinephrine and cortisol, appears to play a critical role in increasing the severity of the viral infection. Recently, Bode et al. reported that stress hyperglycemia (with or without diabetes) is highly correlated with the severity of COVID-19 [17]. Their findings show that stress hyperglycemia is far more commonly associated with the severity of COVID-19 than is the diagnosis of diabetes itself. Another recent large study on hospitalized patients with COVID-19 reported that the mortality of patients with diabetes was significantly higher in those whose blood glucose levels were poorly controlled compared to patients with good glycemic control [18]. Moreover, Sardu et al. showed that in hospitalized patients with previous diabetes or those with stress hyperglycemia, insulin infusion was associated with lower IL6 and d-dimer levels during hospitalization. They concluded that in-patient optimal glucose control is associated with lower risk of severe disease and death in patients with COVID-19 [19].

Hence, it appears that insulin therapy with close monitoring of blood glucose is essential to achieving better outcomes in patients hospitalized with diabetes, hyperglycemia, and COVID19.

\section{USE OF ORAL GLUCOSE-LOWERING MEDICATIONS}

\section{Metformin}

Metformin, a biguanide, was introduced in the 1950 s as the first-line therapy in people with type 2 diabetes. When used as monotherapy, it can lower HbA1c by around 1.5\% [20]. Metformin exerts its function via several cellular pathways, including AMP-activated protein kinase (AMPK). Metformin also reduces the production of reactive oxygen species (ROS), oxidative stress, and DNA damage [21]. In addition to glycemic control, metformin was used in patients with influenza and malaria [22].

The SARS-CoV-2 entry into host cells is mediated via binding to the membrane-bound form of ACE2 followed by internalization of the complex [23]. AMPK has been shown to increase the expression and phosphorylation of ACE2 [24], a process that is potentiated by metformin. Addition of a phosphate group causes conformational and functional changes that could theoretically lead to a decrease in SARS-CoV-2 binding to the receptor [25]. However, upregulation of ACE2 diminishes the deleterious effects of the proinflammatory cascade induced by the renin-angiotensin-aldosterone system (RAS) [26]. 
Metformin exerts an inhibitory effect on the mammalian target of rapamycin (mTOR) signaling cascade [27]. It has been shown that mTOR signaling plays an important role in the pathogenesis of influenza [28].

In vitro and in vivo studies suggest that metformin may have an inhibitory effect on infections with hepatitis $C$ and hepatitis $B$ virus. Increasing insulin sensitivity may be a mechanism that enhances the clinical response to antiviral therapy in chronic hepatitis $C$ patients [29]. Hence, metformin appears to be a safe and effective medication for the fight against SARS$\mathrm{CoV}-2$ in people with T2DM.

\section{Dipeptidyl Peptidase 4 Inhibitors (DPP4i)}

DPP4 is a transmembrane glycoprotein expressed in many tissues, including immune cells. It activates $\mathrm{T}$ cells, upregulates CD86 expression on macrophages and B cells, and stimulates the NF- $\kappa \beta$ pathway, thereby promoting inflammation. Moreover, DPP4 was found to be the same as CD26, a cell surface glycoprotein. CD26 plays an important role in immunology, autoimmunity, and diabetes. In the context of glucose hemostasis, DPP4 regulates glucagon-like peptide 1 (GLP-1) biologic activity.

DPP4i are commonly used to treat patients with T2DM. They increase insulin secretion via endogenous GLP-1, an insulinotropic polypeptide [30, 31]. The effects of DPP4 inhibition on the immune response in patients with T2DM are controversial. It has been reported that the risk of infection does not increase with DPP4i compared to placebo or other glucose-lowering drugs (OGLDs) [32]. Although there are some concerns regarding the risk of nasopharyngitis with treatment with DPP4i, they are not associated with an increased risk of upper respiratory tract infection compared with other OGLDs [33].

DPP4 acts as a functional receptor for MERS$\mathrm{COV}$; however, there is no robust evidence that it is a possible receptor for SARS-COV2 [30]. Since DPP4 plays a co-stimulatory role in T-cell maturation and activation, DPP4 inhibition could be associated with some degree of immune suppression, reducing the risk of acute respiratory complications $[30,31]$.

\section{Sodium Glucose Transporter 2 Inhibitors (SGLT2i)}

SGLT2i demonstrated cardio- and renal-protective benefits in people with T2DM and an elevated risk of cardiovascular disease [34-36].

They prevent the release of proinflammatory cytokines and reduce lactate levels [37, 38]. This might counterbalance the increased lactate level due to cell destruction in COVID-19 infection. Moreover, SGLT2i increase the ACE2 level and as a consequence angiotensin $1-7$, a potent vasodilator [39].

The increased level of angiotensin 1-7 may be protective against acute respiratory distress syndrome (ARDS); however, dehydration should be avoided to reduce the risk of euglycemic diabetic ketoacidosis [40].

\section{Thiazolidinediones (TZDs)}

TZDs enhance the actions of insulin. Insulin resistance is associated with elevated levels of circulating inflammatory biomarkers.

The inflammatory process plays an important role in the initiation and progression of atherosclerosis [41].

However, COVID-19 infection triggers the generation of proinflammatory cytokines and chemokines [1]. It has been reported that respiratory failure is the cause of death in $70 \%$ of fatal COVID-19 cases [42].

Animal studies demonstrated that pioglitazone decreases concentrations of circulating ACE and Ang II and increases concentrations of circulating ACE2 and Ang-(1-7). In addition, it attenuates lung inflammation and fibrosis $[43,44]$. TZDs may positively affect cardiovascular risk factors, including proinflammatory markers, pro-thrombotic markers, and adhesion molecules in T2DM. The anti-inflammatory effect of TZDs ameliorates the prognosis of COVID-19. Considering the potential risk of heart failure with TZD, its probable benefits in the treatment of people with T2DM and 
COVID-19 infection should be further investigated.

\section{Use of Glucagon-like Peptide Receptor Agonist (GLP1RA)}

Acute lung injury is one of the clinical characteristics of patients with severe COVID-19 infections. GLP-1 receptors are present in several organs including the lungs. It has been shown that GLP1 exerts an anti-inflammatory effect and improves surfactant release. Lipopolysaccharide (LPS)-induced polymorphonuclear neutrophil (PMN) extravasation and acute lung injury (ALI) have been shown to be prevented by liraglutide, a GLP1RA in animal models. It restores intercellular tight junctions, prevents PMN-endothelial adhesion, and suppresses PMN migration [42]. The anti-inflammatory action of GLP1RA is mediated through blockade of protein kinase $\mathrm{C}$ or nuclear factorkappa B (NF- $\mathrm{kB})$ and the activation and subsequent expression of inflammatory cytokines. In addition, it activates cAMP-induced adenosine monophosphate-activated protein kinase (AMPK), leading to anti-inflammatory effects on monocyte adhesion [46].

Therefore, it could be hypothesized that GLP-1 RA could alleviate the cascade of inflammatory response and decrease lung injury induced by SARS-CoV-2 infection [47].

\section{MANAGEMENT OF HYPERTENSION IN PATIENTS WITH DIABETES DIAGNOSED WITH COVID-19}

T2DM and insulin resistance are both associated with hypertension. Multiple studies have shown that the presence of hypertension is an important comorbidity that is associated with increases in the prevalence and severity of COVID-19 [48]. A pooled analysis found that in patients with COVID-19, HTN was associated with $\mathrm{a} \sim 2.5$-fold increase in the risk of severity and mortality. Two different studies in China showed that hypertension is the most prevalent comorbidity in patients with COVID-19, being present in $16.9 \%$ and $17.1 \%$ of patients with the disease, respectively $[6,13]$. Another recent study conducted on 5700 patients hospitalized with COVID-19 in New York City showed that $56.6 \%$ of the patients had hypertension [49].

High blood pressure can stimulate sympathetic tone and increase oxidative stress and inflammation, thereby contributing to greater insulin resistance. Hypertension is also highly associated with, and can lead to, cardiovascular and renal disease [50]. Insulin resistance and cardiovascular disease together increase the inflammatory state of the body, which can contribute to and perhaps mediate the increased severity of COVID-19 [51].

\section{USE OF ACE INHIBITORS AND ARBS IN PATIENTS WITH DIABETES AND COVID-19}

Angiotensin-1, which is produced by the action of renin on angiotensinogen, is converted to 8 amino-acid angiotensin-2 peptide by action of angiotensin converting enzyme, ACE-1 (commonly referred to as ACE). Angiotensin-2 stimulates aldosterone secretion, which causes sodium retention and increases the BP. It also stimulates the production of prostaglandins and vascular endothelial growth factor (VEGF), leading to increased vascular permeability, especially in the lungs, thereby increasing the risk of ARDS. Angiotensin-2 also stimulates the release of inflammatory cytokines, which increase the severity of COVID-19 [52, 53].

ACE-2, a membrane-bound enzyme that is expressed in the lungs and many other tissues, converts angiotensin-2 to angiotensin 1-7 [54]. Angiotensin 1-7 peptide has anti-inflammatory properties and decreases insulin resistance; it also causes vasodilation and increases vascular blood flow $[55,56]$.

Some reports have suggested that the use of ACE-1 inhibitors and angiotensin receptor blockers (ARBs) may have deleterious effects on patients with COVID-19 [57]. ACE-1 inhibitors and ARBs are reported to upregulate ACE-2 expression [58-61].

ACE- 2 serves as the "receptor" and the major entry site of SARS-Cov-2 into the pulmonary system; hence, upregulation of ACE- 2 in the 
lungs could lead to increased risk of contracting COVID-19 and its expression in other tissues (including the heart, kidneys, and pancreatic islets), increasing the severity of disease once infected [62-64]. On the other hand, ACE-2 activity results in increased synthesis and levels of angiotensin 1-7. As noted, this seven aminoacid peptide exhibits anti-inflammatory and vasodilatory effects that could have highly beneficial effects on harnessing the inflammation and "cytokine storm" that results from the viral infection [54-57, 64].

Given the above, it seems important that the balance between ACE-1 and ACE- 2 activities should be optimally maintained in patients with COVID-19 [64]. Regulatory bodies and associations including the American College of Cardiology and American Heart Association (ACC/AHA) have recommended continued use of ACE- 1 inhibitors and ARBs in patients with COVID-19. Importantly, these medications are commonly used in patients with heart failure, and their withdrawal can have serious deleterious effects. Discontinuation of these medications can also lead to an increase or fall in blood pressure when another suboptimal agent is used as a substitute $[57,64,65]$.

Despite the above, many patients with T2DM who are treated with these medications have no history of heart failure, and the agents are used primarily for prevention of renal disease. This topic remains controversial, and results of recent studies have shown conflicting results $[66,67]$. More detailed studies are necessary to enlighten this topic. We recommend patients should not stop or change this group of medications.

\section{USE OF CALCIUM CHANNEL BLOCKERS AND COVID-19}

Calcium channel blockers (CCBs) are commonly used in patients with hypertension. A study conducted by Zhang et al. suggested that CCBs might inhibit replication of SARS-CoV-2 virus inside cells by blocking calcium entry and inhibiting their intracellular replication pathway [67]. The elevated intracellular calcium can also stimulate mitochondrial dysfunction, leading to cell stress and apoptosis, which can induce an inflammatory response [68]. Hence, CCBs can have positive effects by decreasing oxidative stress and inflammation by regulating intracellular calcium in patients with T2DM and hypertension [69]. Zhang et al. conducted a retrospective study of 90 patients with COVID19 with hypertension as their sole comorbidity. They studied patients who were being treated with amlodipine besylate versus those using other antihypertensive medications (including ACEIs, ARBs, beta-blockers, and thiazide diuretics) versus those not taking anti-hypertensive medications. The case-fatality rate showed a significant decrease from $26.1 \%$ in patients not treated with amlodipine besylate versus $6.8 \%$ in those being treated with amlodipine besylate $(P=0.022)$ [66].

Based on the available data, CCBs may be beneficial in patients with hypertension and COVID-19. The mechanism appears to be in part due to inhibition of replication of the virus as well as to their anti-inflammatory effects [70]. Perhaps it is advisable to continue these medications once patients with T2DM become afflicted with COVID-19. On the other hand, it is important that most patients severely affected with COVID-19 are hypotensive on admission to the intensive care unit (ICU). More studies are needed to inform judgment for the proper use of these agents.

\section{USE OF BETA-BLOCKERS AND COVID-19}

Beta blockers have been shown to reduce mortality in patients with respiratory failure, ARDS, and septic shock [71, 72]. Some studies suggest that in patients with ARDS, B1-blockers reduce pulmonary vascular flow without a negative effect on systemic hemodynamics, and they appear to decrease endothelial cell damage in the lungs [73].

In addition to their antihypertensive effects in patients with hypertension and COVID-19, it is suggested that beta-blockers might be beneficial at low doses in patients with normal blood pressure and COVID-19 by inhibiting the sympathetic system, which leads to a reduction in 
renin secretion by the kidneys. As noted above, this can cause a downregulation of ACE2 receptors and decrease SARS-COV-2 entry into the pulmonary cells [74]. In a study performed on 12,500 individuals who were tested for COVID-19 in New York City, people who were taking beta-blockers had a lower likelihood for a positive test for the virus [75]. Further studies are necessary to determine the efficacy of beta blockers in patients with COVID-19.

\section{USE OF DIURETICS AND COVID-19}

Patients with COVID-19 and hemodynamic instability or sepsis are likely to need aggressive fluid therapy as inpatients, and many patients admitted with COVID-19 are hypotensive. Consequently, they are vulnerable to adverse outcomes of excessive fluid administration leading to extravascular volume overload and pulmonary edema [76]. Hence, fluid resuscitation should be done very carefully with the goal for cardiac output to become independent of the preload [77].

Some studies evaluated the incidence of acquiring COVID-19 and hospitalization in patients taking diuretics in outpatient settings. In a prospective cohort study on 406,793 participants in the UK, 605 were diagnosed with COVID-19. They evaluated the association of use of antihypertensive medications in patients with COVID-19 and the need for hospitalization. Based on their multivariable model adjusted for age, sex, ethnicity, and hypertension, loop diuretics were the only medications that showed a positive significant relationship to increased hospitalization with COVID-19 [78]. A cohort study from China including 610 patients with COVID-19 compared to 48,667 controls found that prior anti-hypertensive medication therapy with ARBs and diuretics was associated with lower risk of developing COVID-19 [79]. Based on the available data, it is clear that more studies are needed to be able to determine the proper use of diuretics in patients with COVID-19.

\section{USE OF LIPID-LOWERING MEDICATIONS IN PATIENTS WITH T2DM AND COVID-19}

In patients with T2DM and in the era of COVID19 , control of other comorbidities including dyslipidemia and hypertension should be optimized to the degree that is possible and safe [80].

In patients with T2DM, dyslipidemia is present in $30-60 \%$ of case and is characterized by elevated triglyceride, moderately elevated dense LDL and low HDL levels [81]. In these patients, elevated plasma-free fatty acids released from adipose tissue deposit in the liver and some are secreted as VLDL, which leads to hypertriglyceridemia. VLDL turns into smaller but dense LDL particles by losing much of their triglycerides; these denser LDLs in people with T2DM are more atherogenic. Triglycerides also deposit in peripheral tissues and lead to insulin resistance. In addition, free fatty acids directly stimulate Toll-like receptor 4 (TLR4) expressed in immune system cells and can lead to cytokine secretion and inflammation [51, 82-84].

It is well known that statins have anti-inflammatory effects that are independent of their inhibition of HMG-CoA reductase activity. They decrease the expression of TNF- $\alpha$ and other proinflammatory cytokines including interleukin-6 and -1 (IL-6 and IL-1) [85]. However, the anti-inflammatory effect of statins can also lead to upregulation of ACE2 expression [86]. Although increased ACE2 expression can enhance the ability of the virus to enter host cells and cause increased severity of infection in COVID-19 [87], statins should not be discontinued given the probability of a rebound increase in interleukin IL-6 and IL- 1 . Hence, it is generally recommended that statins be continued in patients with T2DM and COVID-19 [77].

Other lipid-lowering agents such as omega-3 and fibrates have anti-inflammatory effects also independent of their lipid-lowering activity; they directly reduce inflammatory markers such as CRP and IL-6, 8 [88, 89]. The anti-inflammatory effects of omega-3 (n-3) polyunsaturated fatty acids (n-3 PUFAs) decrease leukocyte chemotaxis in certain dosages of 
eicosapentaenoic acid (EPA) plus docosahexaenoic acid (DHA) [90]. In addition, they also decrease the production of inflammatory factors including cytokines and chemokines by altering the transcription factors NFא-B and PPAR-y that regulate the expression of inflammatory genes [88]. There is some evidence that fibrates are effective for primary and secondary prevention of CVD. They mainly reduce plasma triglyceride and increase HDL levels by activating peroxisome proliferator-activated receptor (PPAR)- $\alpha$ [91]; this leads to reduction in insulin resistance in peripheral tissues.

There is a paucity of evidence to help inform the proper use of lipid-lowering agents in patients with T2DM who have developed COVID-19. Nevertheless, based on the above information, we recommended that statins and other lipid-lowering medications be continued in patients with T2DM. In cases where triglyceride levels become extremely elevated during the infection, more aggressive measures should be taken to control the hypertriglyceridemia.

\section{USE OF ANTIPLATELET/ ANTITHROMBOTIC MEDICATIONS IN PATIENTS WITH T2DM AND COVID-19}

Several pathophysiologic mechanisms link COVID-19 infection with thrombotic and thromboembolic diseases. Systemic inflammation, cytokine storm, and hypoxia predispose patients to thromboembolic events. On the other hand, investigational therapies that are currently used in treatment of these patients might have drug interactions with antiplatelet and antithrombotic medicines. Consequently, the prothrombotic state might cause disseminated intravascular coagulation (DIC), venous thromboembolism, and myocardial infarction [92].

For patients who are taking antithrombotic medicines, antithrombotic agents should be continued. In the absence of any contraindication, venous thromboembolism prophylaxis should be administered to all hospitalized patients with COVID-19 infection without DIC.
Monitoring of biomarkers such as D-dimer is not recommended to monitor anticoagulant therapy. However, dose adjustment is necessary for patients with moderate or severe COVID-19 and DIC, without overt bleeding, on chronic anticoagulation [93].

\section{CONCLUSION}

SARS-CoV-2 infection is a global concern with a high rate of both morbidity and mortality especially in people who are at high cardiovascular risk. There is currently not sufficient evidence regarding the most appropriate management of CVD risk in patients with diabetes during COVID-19 infection. Personalized therapeutic strategies and optimal glucose control should be formulated based on age, disease severity, and presence of diabetes-related complications.

\section{ACKNOWLEDGEMENTS}

The authors thank Ms. O. Asadi for her helpful technical comments during manuscript preparation.

Funding. No funding or sponsorship was received for this study or publication of this article.

Authorship. All named authors meet the International Committee of Medical Journal Editors (ICMJE) criteria for authorship for this article, and take responsibility for the integrity of the work as a whole. They have given their approval for this version to be published.

Disclosures. Leili Rahimi, Mohammad E. Khamseh, Mojtaba Malek, and Faramarz IsmailBeigi have nothing to disclose.

Compliance with Ethics Guidelines. This article is based on previously conducted studies and does not contain any studies with human participants or animals performed by any of the authors. 
Open Access. This article is licensed under a Creative Commons Attribution-NonCommercial 4.0 International License, which permits any non-commercial use, sharing, adaptation, distribution and reproduction in any medium or format, as long as you give appropriate credit to the original author(s) and the source, provide a link to the Creative Commons licence, and indicate if changes were made. The images or other third party material in this article are included in the article's Creative Commons licence, unless indicated otherwise in a credit line to the material. If material is not included in the article's Creative Commons licence and your intended use is not permitted by statutory regulation or exceeds the permitted use, you will need to obtain permission directly from the copyright holder. To view a copy of this licence, visit http://creativecommons.org/licenses/by$\mathrm{nc} / 4.0 /$.

\section{REFERENCES}

1. Huang C, Wang Y, Li X, Ren L, Zhao J, Hu Y, et al. Clinical features of patients infected with 2019 novel coronavirus in Wuhan, China. Lancet. 2020;395(10223):497-506.

2. Organization WH. Naming the coronavirus disease (COVID-19) and the virus that causes it. 2020. https://www.whoint/emergencies/diseases/novelcoronavirus-2019/technical-guidance/naming-thecoronavirus-disease-(covid-2019)-and-the-virusthat-causes-it. 2020.

3. Organization WH. Rolling updates on coronavirus disease (COVID-19). 2020.

4. Organization WH. Coronavirus disease (COVID-19) Situation Report-124, 23 May 2020.

5. Yanga J, Zhenga Y, Goua X, Pua K, Chena Z, Guoa $Q$, et al. Prevalence of comorbidities and its effects in patients infected with SARS-CoV-2: a systematic review and meta-analysis. Int J Infect Dis. 2020;94: 91-5.

6. Chen Y, Gong X, Wang L, Guo J. Effects of hypertension, diabetes and coronary heart disease on COVID-19 diseases severity: a systematic review and meta-analysis. medRxiv. 2020.

7. Zheng Z, Peng F, Xu B, Zhao J, Liu H, Peng J, et al. Risk factors of critical and mortal COVID-19 cases: a systematic literature review and meta-analysis. J Infect. $2020 ; 28(15): 12$.

8. WHO-China Joint Mission. Report of the WHOChina Joint Mission on Corona virus Disease 2019 (COVID-19) (PDF). World Health Organization. 2020. https://www.who.int/docs/default-source/ coronaviruse/who-china-joint-mission-on-covid19-final-report.pdf.

9. Hespanhol V, Bárbara C. Pneumonia mortality, comorbidities matter? Pulmonology. 2020;26(3): 123-9.

10. Roca-Ho H, Riera M, Palau V, Pascual J, Soler MJ. Characterization of ACE and ACE2 expression within different organs of the NOD mouse. Int J Mol Sci. 2017;18(3):563.

11. Yang J-K, Lin S-S, Ji X-J, Guo L-M. Binding of SARS coronavirus to its receptor damages islets and causes acute diabetes. Acta Diabetol. 2010;47(3):193-9.

12. Knapp S. Diabetes and infection: is there a link? A mini-review. Gerontology. 2013;59(2):99-104.

13. Guan W-J, Ni Z-Y, Hu Y, Liang W-H, Ou C-Q, He $\mathrm{J}-\mathrm{X}$, et al. Clinical characteristics of coronavirus disease 2019 in China. N Engl J Med. 2020;382(18): 1708-20.

14. Petrie JR, Guzik TJ, Touyz RM. Diabetes, hypertension, and cardiovascular disease: clinical insights and vascular mechanisms. Can J Cardiol. 2018;34(5):575-84. https://doi.org/10.1016/j.cjca. 2017.12.005.

15. Bode B, Garrett V, Messler J, McFarland R, Crowe J, Booth R, et al. Glycemic characteristics and clinical outcomes of COVID-19 patients hospitalized in the United States. J Diabetes Sci Technol. 2020. https:// doi.org/10.1177/1932296820924469.

16. Petrie JR, Guzik TJ, Touyz RM. Diabetes, hypertension, and cardiovascular disease: clinical insights and vascular mechanisms. Can J Cardiol. 2018;34(5):575-84.

17. Rojas LBA, Gomes MB. Metformin: an old but still the best treatment for type 2 diabetes. Diabetology Metab Syndr. 2013;5(1):6. https://doi.org/10.1186/ 1758-5996-5-6.

18. Guimarães TA, Farias LC, Santos ES, de Carvalho Fraga CA, Orsini LA, de Freitas Teles L, et al. Metformin increases PDH and suppresses HIF- $1 \alpha$ under hypoxic conditions and induces cell death in oral squamous cell carcinoma. Oncotarget. 2016;7(34): 55057-68. https://doi.org/10.18632/oncotarget. 10842. 
19. Sardu C, D'Onofrio N, Balestrieri ML, Barbieri M, Rizzo MR, Messina V, et al. Outcomes in patients with hyperglycemia affected by Covid-19: can we do more on glycemic control? Diabetes Care. 2020. https://doi.org/10.2337/dc20-0723.

20. Rojas LBA, Gomes MB. Metformin: an old but still the best treatment for type 2 diabetes. Diabetol Metab Syndrome. 2013;5(1):6.

21. Guimarães TA, Farias LC, Santos ES, de Carvalho Fraga CA, Orsini LA, de Teles Freitas L, et al. Metformin increases PDH and suppresses HIF- $1 \alpha$ under hypoxic conditions and induces cell death in oral squamous cell carcinoma. Oncotarget. 2016;7(34): 55057.

22. Amin S, Lux A, O'Callaghan F. The journey of metformin from glycaemic control to mTOR inhibition and the suppression of tumour growth. Br J Clin Pharmacol. 2019;85(1):37-46.

23. South AM, Diz DI, Chappell MC. COVID-19, ACE2, and the cardiovascular consequences. Am J Physiol Heart Circ Physiol. 2020;318(5):H1084-90.

24. Liu J, Li X, Lu Q, Ren D, Sun X, Rousselle T, et al. AMPK: a balancer of the renin-angiotensin system. Biosci Rep. 2019;39(9):BSR20181994.

25. Plattner F, Bibb JA. Serine and threonine phosphorylation. Basic neurochemistry. Amsterdam: Elsevier; 2012. p. 467-92.

26. Chen Y, Gu F, Guan J-L. Metformin might inhibit virus through increasing insulin sensitivity. Chin Med J. 2018;131(3):376-7. https://doi.org/10.4103/ 0366-6999.223856.

27. Wang Y, Zhang M, Duan X, Zhou S, Ermek T, Wang $Y$, et al. Effects of antidiabetic drug metformin on human breast carcinoma cells with different estrogen receptor expressing in vitro. $\mathrm{Xi}$ bao yu fen $\mathrm{zi}$ mian yi xue za zhi $=$ Chin J Cell Mol Immunol. 2011;27(3):253-6.

28. Ohnuma K, Takahashi N, Yamochi T, Hosono O, Dang NH, Morimoto C. Role of CD26/dipeptidyl peptidase IV in human $\mathrm{T}$ cell activation and function. Front Biosci. 2008;13:2299-310. https://doi. org/10.2741/2844.

29. Chen Y, Gu F, Guan J-L. Metformin might inhibit virus through increasing insulin sensitivity. Chin Med J. 2018;131(3):376.

30. Karagiannis T, Paschos P, Paletas K, Matthews DR, Tsapas A. Dipeptidyl peptidase- 4 inhibitors for treatment of type 2 diabetes mellitus in the clinical setting: systematic review and meta-analysis. BMJ. 2012;344:e1369. https://doi.org/10.1136/bmj. e1369.
31. Ohnuma K, Takahashi N, Yamochi T, Hosono O, Dang NH, Morimoto C. Role of CD26/dipeptidyl peptidase IV in human $\mathrm{T}$ cell activation and function. Front Biosci. 2008;13(2):299.

32. Yang W, Cai X, Han X, Ji L. DPP-4 inhibitors and risk of infections: a meta-analysis of randomized controlled trials. Diabetes Metab Res Rev. 2016;32(4):391-404.

33. Karagiannis T, Paschos P, Paletas K, Matthews DR, Tsapas A. Dipeptidyl peptidase-4 inhibitors for treatment of type 2 diabetes mellitus in the clinical setting: systematic review and meta-analysis. BMJ. 2012;344:e1369.

34. Zinman B, Wanner C, Lachin JM, Fitchett D, Bluhmki E, Hantel S, et al. Empagliflozin, cardiovascular outcomes, and mortality in type 2 diabetes. N Engl J Med. 2015;373(22):2117-28.

35. Neal B, Perkovic V, Mahaffey KW, De Zeeuw D, Fulcher G, Erondu N, et al. Canagliflozin and cardiovascular and renal events in type 2 diabetes. N Engl J Med. 2017;377(7):644-57.

36. Wiviott SD, Raz I, Bonaca MP, Mosenzon O, Kato ET, Cahn A, et al. Dapagliflozin and cardiovascular outcomes in type 2 diabetes. $\mathrm{N}$ Engl J Med. $2019 ; 380(4): 347-57$.

37. Dekkers CC, Petrykiv S, Laverman GD, Cherney DZ, Gansevoort RT, Heerspink HJ. Effects of the SGLT-2 inhibitor dapagliflozin on glomerular and tubular injury markers. Diabetes Obes Metab. 2018;20(8): 1988-93.

38. Kappel BA, Lehrke M, Schütt K, Artati A, Adamski J, Lebherz C, et al. Effect of empagliflozin on the metabolic signature of patients with type 2 diabetes mellitus and cardiovascular disease. Circulation. 2017;136(10):969-72.

39. Kawanami D, Matoba K, Takeda Y, Nagai Y, Akamine $\mathrm{T}$, Yokota $\mathrm{T}$, et al. SGLT2 inhibitors as a therapeutic option for diabetic nephropathy. Int J Mol Sci. 2017;18(5):1083.

40. Cure E, Cure MC. Can dapagliflozin have a protective effect against COVID-19 infection? A hypothesis. Diabetes Metab Syndrome. 2020;14(4):405.

41. Lebovitz HE. Thiazolidinediones: the forgotten diabetes medications. Curr Diabetes Rep. 2019;19(12):151.

42. Xu J, Wei G, Wang J, Zhu J, Yu M, Zeng X, Wang H, Xie W, Kong H. Glucagon-like peptide- 1 receptor activation alleviates lipopolysaccharideinduced acute lung injury in mice via maintenance of endothelial barrier function. Lab Invest. 2019;99(4):577-87. https://doi. org/10.1038/s41374-018-0170-0. 
43. Kutsukake M, Matsutani T, Tamura K, Matsuda A, Kobayashi M, Tachikawa E, et al. Pioglitazone attenuates lung injury by modulating adipose inflammation. J Surg Res. 2014;189(2):295-303.

44. Zhang W, Li C, Liu B, Wu R, Zou N, Xu Y-Z, et al. Pioglitazone upregulates hepatic angiotensin converting enzyme 2 expression in rats with steatohepatitis. Ann Hepatol. 2013;12(6):892-900.

45. Richardson S, Hirsch JS, Narasimhan M, Crawford JM, McGinn T, Davidson KW, et al. Presenting characteristics, comorbidities, and outcomes among 5700 patients hospitalized with COVID-19 in the New York City area. JAMA. 2020;323(20): 2052-9. https://doi.org/10.1001/jama.2020.6775.

46. Salvetti A, Brogi G, Di Legge V, Bernini G. The interrelationship between insulin resistance and hypertension. Drugs. 1993;46(Suppl 2):149-59. https:// doi.org/10.2165/00003495-199300462-00024.

47. Rajpal A, Rahimi L, Ismail-Beigi F. COVID-19 and diabetes: factors leading to high morbidity and mortality. J Diabetes (Submitted).

48. Tikellis C, Thomas M. Angiotensin-converting enzyme 2 (ACE2) is a key modulator of the renin angiotensin system in health and disease. Int $\mathrm{J}$ Peptides. 2012;2012:256294. https://doi.org/10. $1155 / 2012 / 256294$.

49. Salvetti A, Brogi G, Di Legge V, Bernini G. The interrelationship between insulin resistance and hypertension. Drugs. 1993;46(2):149-59.

50. Vickers C, Hales P, Kaushik V, Dick L, Gavin J, Tang J, et al. Hydrolysis of biological peptides by human angiotensin-converting enzyme-related carboxypeptidase. J Biol Chem. 2002;277(17):14838-43. https:// doi.org/10.1074/jbc.M200581200.

51. Tikellis C, Thomas M. Angiotensin-converting enzyme 2 (ACE2) is a key modulator of the renin angiotensin system in health and disease. Int J Pept. 2012.

52. Kassiri Z, Zhong J, Guo D, Basu R, Wang X, Liu PP, et al. Loss of angiotensin-converting enzyme 2 accelerates maladaptive left ventricular remodeling in response to myocardial infarction. Circ Heart Fail. 2009;2(5):446-55.

53. Vickers C, Hales P, Kaushik V, Dick L, Gavin J, Tang J, et al. Hydrolysis of biological peptides by human angiotensin-converting enzyme-related carboxypeptidase. J Biol Chem. 2002;277(17):14838-43.

54. Bornstein SR, Dalan R, Hopkins D, Mingrone G, Boehm BO. Endocrine and metabolic link to coronavirus infection. Nat Rev Endocrinol. 2020;297: $1-2$.
55. Simoes e Silva A, Silveira K, Ferreira A, Teixeira M. ACE2, angiotensin-(1-7) and $M$ as receptor axis in inflammation and fibrosis. $\mathrm{Br} \mathrm{J}$ Pharmacol. 2013;169(3):477-92.

56. Brett AS, Rind DM. ACE inhibitors and ARBs during the COVID-19 pandemic. NEJM Journal Watch. April 9, 2020. https://www.jwatch.org/na51345/ 2020/04/09/ace-inhibitors-and-arbs-during-covid19-pandemic.

57. Ferrario CM, Jessup J, Chappell MC, Averill DB, Brosnihan KB, Tallant EA, et al. Effect of angiotensin-converting enzyme inhibition and angiotensin II receptor blockers on cardiac angiotensinconverting enzyme 2. Circulation. 2005;111(20): 2605-10. https://doi.org/10.1161/CIRCULAT IONAHA.104.510461.

58. Li XC, Zhang J, Zhuo JL. The vasoprotective axes of the renin-angiotensin system: physiological relevance and therapeutic implications in cardiovascular, hypertensive and kidney diseases. Pharmacol Res. 2017;125:21-38.

59. Ishiyama Y, Gallagher PE, Averill DB, Tallant EA, Brosnihan KB, Ferrario CM. Upregulation of angiotensin-converting enzyme 2 after myocardial infarction by blockade of angiotensin II receptors. Hypertension. 2004;43(5):970-6.

60. Ferrario CM, Jessup J, Chappell MC, Averill DB, Brosnihan KB, Tallant EA, et al. Effect of angiotensin-converting enzyme inhibition and angiotensin II receptor blockers on cardiac angiotensinconverting enzyme 2. Circulation. 2005;111(20): 2605-10.

61. Wu Y-C, Chen C-S, Chan Y-J. The outbreak of COVID-19: an overview. J Chin Med Assoc. 2020;83(3):217.

62. Rothan HA, Byrareddy SN. The epidemiology and pathogenesis of coronavirus disease (COVID-19) outbreak. J Autoimmun. 2020:102433.

63. Vaduganathan M, Vardeny O, Michel T, McMurray JJ, Pfeffer MA, Solomon SD. Renin-angiotensin-aldosterone system inhibitors in patients with Covid19. N Engl J Med. 2020;382(17):1653-9.

64. Horng T. Calcium signaling and mitochondrial destabilization in the triggering of the NLRP3 inflammasome. Trends Immunol. 2014;35(6): 253-61. https://doi.org/10.1016/j.it.2014.02.007.

65. Kim HJ, Han SJ, Kim DJ, Jang HC, Lim S, Choi SH, et al. Effects of valsartan and amlodipine on oxidative stress in type 2 diabetic patients with hypertension: a randomized, multicenter study. Korean J Intern Med. 2017;32(3):497-504. https:// doi.org/10.3904/kjim.2015.404. 
66. Zhang P, Zhu L, Cai J, Lei F, Qin J-J, Xie J, et al. Association of inpatient use of angiotensin converting enzyme inhibitors and angiotensin II receptor blockers with mortality among patients with hypertension hospitalized with COVID-19. Circ Res. 2020;126:1671-81. https://doi.org/10. 1161/CIRCRESAHA.120.317134.

67. Horng T. Calcium signaling and mitochondrial destabilization in the triggering of the NLRP3 inflammasome. Trends Immunol. 2014;35(6): 253-61.

68. Kim HJ, Han SJ, Kim DJ, Jang HC, Lim S, Choi SH, et al. Effects of valsartan and amlodipine on oxidative stress in type 2 diabetic patients with hypertension: a randomized, multicenter study. Korean J Intern Med. 2017;32(3):497.

69. Coppola S, Froio S, Chiumello D. $\beta$-blockers in critically ill patients: from physiology to clinical evidence. Crit Care. 2015;19(1):119. https://doi. org/10.1186/s13054-015-0803-2.

70. Tan K, Harazim M, Tang B, Mclean A, Nalos M. The association between premorbid beta blocker exposure and mortality in sepsis-a systematic review. Crit Care. 2019;23(1):298.

71. Al-Qadi MO, Kashyap R. A42 ARDS: RISK, TREATMENT, AND OUTCOMES: effect of chronic beta blockers use on sepsis-related acute respiratory distress syndrome. Am J Respir Crit Care Med. 2015;191:1.

72. Coppola S, Froio S, Chiumello D. $\beta$-blockers in critically ill patients: from physiology to clinical evidence. Annual Update in Intensive Care and Emergency Medicine 2015: Springer; 2015. p. 139-52.

73. Vasanthakumar N. Can beta-adrenergic blockers be used in the treatment of COVID-19? Med Hypotheses. 2020;5(142):109809.

74. Reynolds HR, Adhikari S, Pulgarin C, Troxel AB, Iturrate $\mathrm{E}$, Johnson SB, et al. Renin-angiotensin-aldosterone system inhibitors and risk of Covid-19. N Engl J Med. 2020.

75. Kazory A, Ronco C, McCullough PA, editors. SARSCoV-2 (COVID-19) and intravascular volume management strategies in the critically ill. Baylor University Medical Center Proceedings; 2020: Taylor \& Francis.

76. Vincent J-L, De Backer D. Circulatory shock. N Engl J Med. 2013;369(18):1726-34.

77. Khawaja AP, Warwick AN, Hysi PG, Kastner A, Dick A, Khaw PT, et al. Associations with covid-19 hospitalisation amongst 406,793 adults: the UK Biobank prospective cohort study. medRxiv. 2020.

78. Yan H, Valdes AM, Vijay A, Wang S, Liang L, Yang $S$, et al. Role of drugs affecting the renin-angiotensin-aldosterone system on susceptibility and severity of COVID-19: a large case-control study from Zheijang Province, China. medRxiv. 2020.

79. Zheng S, Xu H, Zhou H, Ren X, Han T, Chen Y, et al. Associations of lipid profiles with insulin resistance and $\beta$ cell function in adults with normal glucose tolerance and different categories of impaired glucose regulation. PLOS ONE. 2017;12(2):e0172221. https://doi.org/10.1371/journal.pone.0172221. eCollection.2017.

80. Olejnik J, Hume AJ, Mühlberger E. Toll-like receptor 4 in acute viral infection: Too much of a good thing. PLoS Pathog. 2018;14(12):e1007390. https:// doi.org/10.1371/journal.ppat.1007390.

81. Ormazabal V, Nair S, Elfeky O, Aguayo C, Salomon $C$, Zuñiga FA. Association between insulin resistance and the development of cardiovascular disease. Cardiovasc Diabetol. 2018;17(1):122.

82. Shin YH, Min JJ, Lee J-H, Kim E-H, Kim GE, Kim $\mathrm{MH}$, et al. The effect of fluvastatin on cardiac fibrosis and angiotensin-converting enzyme-2 expression in glucose-controlled diabetic rat hearts. Heart Vessels. 2017;32(5):618-27. https://doi.org/ 10.1007/s00380-016-0936-5.

83. Li G, He X, Zhang L, Ran Q, Wang J, Xiong A, et al. Assessing ACE2 expression patterns in lung tissues in the pathogenesis of COVID-19. J Autoimmun. 2020. https://doi.org/10.1016/j.jaut.2020.102463.

84. Diamantis E, Kyriakos G, Victoria Quiles-Sanchez L, Farmaki P, Troupis T. The anti-inflammatory effects of statins on coronary artery disease: an updated review of the literature. Curr Cardiol Rev. 2017;13(3):209-16.

85. Shin YH, Min JJ, Lee J-H, Kim E-H, Kim GE, Kim $\mathrm{MH}$, et al. The effect of fluvastatin on cardiac fibrosis and angiotensin-converting enzyme-2 expression in glucose-controlled diabetic rat hearts. Heart Vessels. 2017;32(5):618-27.

86. Li G, He X, Zhang L, Ran Q, Wang J, Xiong A, et al. Assessing ACE2 expression patterns in lung tissues in the pathogenesis of COVID-19. J Autoimmun. 2020:102463.

87. Calder PC. Omega-3 fatty acids and inflammatory processes. Nutrients. 2010;2(3):355-74.

88. Kim NH, Kim SG. Fibrates revisited: potential role in cardiovascular risk reduction. Diabetes Metab J. 2020;44(2):213. 
89. Calder PC. Omega-3 polyunsaturated fatty acids and inflammatory processes: nutrition or pharmacology? Br J Clin Pharmacol. 2013;75(3):645-62.

90. Belfort R, Berria R, Cornell J, Cusi K. Fenofibrate reduces systemic inflammation markers independent of its effects on lipid and glucose metabolism in patients with metabolic syndrome. J Clin Endocrinol Metab. 2010;95(2):829-36.

91. Bikdeli B, Madhavan MV, Jimenez D, Chuich T, Dreyfus I, Driggin E, et al. COVID-19 and thrombotic or thromboembolic disease: implications for prevention, antithrombotic therapy, and follow-up. J Am Coll Cardiol. 2020;75(23):2950.

92. Barnes GD, Burnett A, Allen A, Blumenstein M, Clark NP, Cuker A, et al. Thromboembolism and anticoagulant therapy during the COVID-19 pandemic: interim clinical guidance from the anticoagulation forum. J Thromb Thromb. 2020. https:// doi.org/10.1007/s11239-020-02138-z. 